\title{
Effect of Different Parameters of U-Concrete Jacketing on Behavior of Strengthened Beam
}

\author{
Eng. Bandar Fawaz Al-Harbi ${ }^{1}$, Dr. Gamal A. Al-Saadi ${ }^{2}$, Dr. Ahmed F. Elragi ${ }^{2}$ \\ ${ }^{1}$ Faculty Member, Technical and Vocational Training Corporation (TVTC), PG, Civil Engineering Department \\ College of Engineering, Qassim University, Saudi Arabia \\ bandarf@tvtc.gov.sa \\ ${ }^{2}$ Assistant Professor, Civil Engineering Department \\ College of Engineering, Qassim University, Saudi Arabia
}

\begin{abstract}
With the continuous developments of civil engineering practices in general and structural engineering in particular, engineers have been investigating the rehabilitation/strengthening techniques of existing structures to save them and/or increase their load capacity by raising the efficiency of the structural elements of existing buildings such as beams and columns. This technique used for different purposes such as in increasing the lifetime of these structures, adapting with the change of functionality of the building, and to overcome the error design. The objective of this study is to investigate the effect of changing some properties of reinforced concrete jacket $u$-shaped which used for strengthening reinforced concrete (RC) beams. This study focused on increasing the load capacity of beams in existing buildings. The effect of changing yield strength, concrete strength, rebar size, and thickness of RC jackets on the load capacity of beams have been investigated aiming at identifying the best practices in this regard using Finite Element Method (FEM)-based numerical analysis utilizing ANSYS software. Moreover, reinforcement stress is discussed. The results of the numerical analysis have verified experimentally utilizing previous research. It is noticed that some of the proposed changes for RC jackets contribute in improving of performance for U-concrete jacketing technique to be a more effective technique to strengthen the existing beams which shall help engineers in practical use in the field.
\end{abstract}

Keywords: Strengthening, Reinforced concrete beams, U-concrete jacketing, Numerical analysis, ANSYS.

\section{Introduction}

Firstly, the rehabilitation and strengthening of existing structures have common use in construction field to increase load capacity of structures by raising efficiency of structural elements of buildings such as beams and columns. This technique contributes in cost saving and increasing longevity of structures.

Rehabilitation and strengthening is an effective alternative to rebuilding or reconstruction of existing structures. In addition, there are many researches that studied different ways of rehabilitating to increase the strength and load capacity of concrete beams considering them as basic structural elements [1].

Strengthening of existing structures considers among the most important challenges in civil engineering in recent years. Furthermore, improving resistance or stiffness to resist additional loads and increasing the load-carrying capacity for higher allowable loads are possible reasons for using strengthening techniques [2].

The strengthening of the structural elements of existing buildings is considered the most significant topic in the field of rehabilitation of structures [3].

Most of the studies focused on FRP technique because of its ability to increase strength without significantly increasing in dead load of structures (D.L); this urges a need to study other methods of confinement [4].

The research depends on the use of concrete jacketing for strengthening constructed RC beams and study their structural behavior. It has been chosen since engineers are familiar with it and it does not require skilled labor compared to the other methods [5].

Rehabilitation of existing structures using concrete jacketing is required in some situations such as [6]:

1. Buildings that are not designed to resist seismic forces or designed with old seismic codes.

2. The low quality of the constructions.

3. Changing the use or functionality of structures. 
4. Weak members of soft story buildings.

5. Weak members of monumental buildings.

Strengthening technique may be required due to safety demands or changes in the usage of the structure. In addition, they indicate this technique is more economical for structures compared with demolishing and rebuilding [7].

Concrete jacketing of beams involves increasing cross-sectional area of reinforced concrete whether one or more face [8]. Generally, there are two purposes of using concrete jacketing; first, is to increase shear capacity, second, is to improve flexural strength for structural elements [6].

This study will focus on structural behavior of RC beams with partial concrete jacketing, especially the load capacity through determine the applied load for each strengthened beam by numerical analysis utilizing ANSYS ${ }^{\circledR}$ software [9].

Importance of the concrete jacketing in this numerical study is to strengthen RC beams in term of load capacity through increasing value of applied loads. Regardless of the cause of the strength shortage whether it is a design error or change the function of the building or so on.

It is significant to introduce details of the experimental tests that carried out by Chalioris et al. [10], since these were used for verification of the numerical modelling [11].

This previous research discussed the behavior of RC beams that were strengthened using concrete jacketing. Selfcompacting concrete (SCC) has been used in this experimental test because it does not require compaction by vibration [12]. The jackets consisted of thin layers of fine-aggregate concrete and not exceeding $25 \mathrm{~mm}$ in thickness. The research illustrated that performance efficiency with thin RC jackets is higher than conventional RC jackets.

Chalioris et al. [10] conducted on RC beams that were constructed and subjected to monotonic loading. The beams were strengthened using U-shaped SCC jacket. The concrete jackets included small diameter steel bars and U-formed stirrups.

Moreover, experimental results confirmed that the load capacity and overall performance of RC beams with SCC jacketing was greatly improved compared with the initial situation by $50 \%$. In addition, analytical results are in a good agreement with the experimental ones.

The present study focused on the effect of changing of some parameters, in other words, proposed changes in properties of RC jackets that may become a choice for engineers in practical uses in order to improve the efficiency of strengthened $\mathrm{RC}$ beams. The purpose of the study is to investigate the influence of specific parameters on the load capacity of the strengthened RC beams.

\section{Numerical Modeling}

The numerical modeling achieved using ANSYS [9] and the model details in the present study are taken the same as the previous researches Chalioris et al. [10] and Al-Harbi et al. [11] which includes experimental test (U-jacket) (Figure 1), especially model of the beam B2J-U which chosen as a control beam and to verify the finite element models through it. Results of the nonlinear finite element models in the present study have checked by comparing with the corresponding results of that experimental test that available in the references [10] and [11].

\subsection{Geometry and Definition of Numerical Models}

Fig. 1 and Table 1 represent the cross-section and assumed reinforcement details for the numerical models of the RC beams B2 \& B2J. 


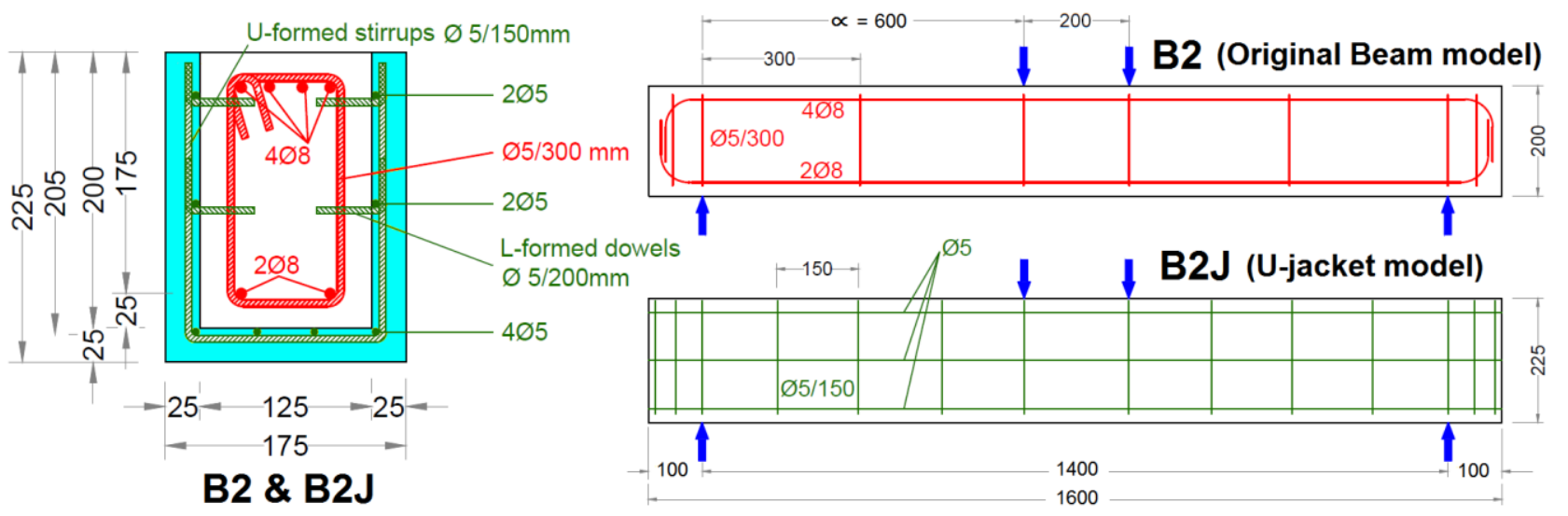

Fig. 1: Cross-sectional and reinforcement details of the beam models B2 \& B2J (all dimension in $\mathrm{mm}$ ).

Table 1: Geometrical, mechanical and steel reinforcement characteristics of the beam models.

\begin{tabular}{|c|c|c|c|c|c|c|c|c|c|c|}
\hline \multirow{3}{*}{$\begin{array}{l}\text { Initial } \\
\text { beam } \\
\text { name }\end{array}$} & \multicolumn{7}{|c|}{ Characteristics of the initial beams } & \multirow{3}{*}{\multicolumn{3}{|c|}{$\begin{array}{l}\boldsymbol{f}_{\mathrm{c}, \mathrm{o}} / \boldsymbol{f}_{\mathrm{ct}, \mathrm{o}} \\
(\mathrm{MPa})\end{array}$}} \\
\hline & \multirow{2}{*}{$\begin{array}{l}\mathrm{b}_{\mathrm{o}} / \mathrm{h}_{\mathrm{o}} \\
(\mathrm{mm})\end{array}$} & \multirow{2}{*}{$\begin{array}{c}\mathrm{d}_{\mathrm{o}} \\
(\mathrm{mm})\end{array}$} & \multirow{2}{*}{$\mathrm{a} / \mathrm{d}_{\mathrm{o}}$} & \multicolumn{3}{|c|}{ Longitudinal bars } & \multirow{2}{*}{ Stirrups } & & & \\
\hline & & & & Top & \multicolumn{2}{|c|}{ Bottom } & & & & \\
\hline B2 & $125 / 200$ & 175 & 3.43 & $\begin{array}{c}4 \phi 8 \\
(0.92 \%)\end{array}$ & \multicolumn{2}{|c|}{$\begin{array}{c}2 \phi 8 \\
(0.46 \%)\end{array}$} & $\begin{array}{l}\phi 5 / 300 \\
(0.10 \%)\end{array}$ & \multicolumn{3}{|c|}{$28.2 / 2.15$} \\
\hline \multirow{3}{*}{$\begin{array}{c}\text { Jacketed } \\
\text { beam } \\
\text { name }\end{array}$} & \multicolumn{7}{|c|}{ Characteristics of the jackets and the jacketed beams } & \multirow{3}{*}{$\begin{array}{l}\boldsymbol{f}_{\mathrm{c}, \mathrm{J}} / \boldsymbol{f}_{\mathrm{c}, \mathrm{J}} \\
(\mathrm{MPa})\end{array}$} & \multirow{2}{*}{\multicolumn{2}{|c|}{$\begin{array}{c}\text { Total } \\
\text { reinforcement }\end{array}$}} \\
\hline & \multirow{2}{*}{$\begin{array}{l}\mathrm{b}_{\mathrm{J}} / \mathrm{h}_{\mathrm{J}} \\
(\mathrm{mm})\end{array}$} & \multirow{2}{*}{$\begin{array}{c}\mathrm{d}_{\mathrm{J}} \\
(\mathrm{mm})\end{array}$} & \multirow{2}{*}{$\mathrm{a} / \mathrm{d}_{\mathrm{J}}$} & \multicolumn{3}{|c|}{ Longitudinal bars } & \multirow{2}{*}{$\begin{array}{c}\text { U- } \\
\text { formed } \\
\text { Stirrups }\end{array}$} & & & \\
\hline & & & & Top & Middle & Bottom & & & $\rho_{1}(\%)$ & $\rho_{\mathrm{t}}(\%)$ \\
\hline B2J-U & $175 / 225$ & 205 & 2.93 & $\begin{array}{c}2 \phi 5 \\
(0.11 \%)\end{array}$ & $\begin{array}{c}2 \phi 5 \\
(0.11 \%)\end{array}$ & $\begin{array}{c}4 \phi 5 \\
(0.22 \%)\end{array}$ & $\begin{array}{l}\Phi 5 / 150 \\
(0.15 \%)\end{array}$ & $42.8 / 3.72$ & 0.50 & 0.22 \\
\hline
\end{tabular}

This study depends on changing material properties of the numerical model (U-jacket model) and it seeks to discover the influence of the parameters under study on the numerical model in term of reinforcement and concrete properties. Furthermore, it aims to adopt the model with Saudi Building Code (SBC) [13] as well as to help engineers recognize of influence the concrete strength used in RC jackets. In addition, it includes change of rebar type used in the RC jackets from 5 $\mathrm{mm}$ in the U-jacket model to $8 \mathrm{~mm}$, and $10 \mathrm{~mm}$. Also, it includes change of jacket thickness from $2.5 \mathrm{~cm}$ to $5 \mathrm{~cm}$, and $10 \mathrm{~cm}$.

There are nine models have been discussed in this study as well as the original beam model (B2) and the U-jacket model (B2J-U):

1. Case. a: U-jacket beam model with fy equals $420 \mathrm{MPa}$.

2. Case. b: U-jacket beam model with rebar $8 \mathrm{~mm}$ in the RC jacket.

3. Case. c: U-jacket beam model with rebar $10 \mathrm{~mm}$ in the RC jacket.

4. Case. d: U-jacket beam model with f'c for original beam equals $20 \mathrm{MPa}$ and $40 \mathrm{MPa}$ for jacket.

5. Case. e: U-jacket beam model with f'c for original beam equals $20 \mathrm{MPa}$ and $50 \mathrm{MPa}$ for jacket.

6. Case. $\mathrm{f}$ : $\mathrm{U}$-jacket beam model with f'c for original beam equals $20 \mathrm{MPa}$ and $60 \mathrm{MPa}$ for jacket.

7. Case. g: U-jacket beam model with jacket thickness equals $2.5 \mathrm{~cm}$.

8. Case. h: U-jacket beam model with jacket thickness equals $5 \mathrm{~cm}$.

9. Case. i: U-jacket beam model with jacket thickness equals $10 \mathrm{~cm}$.

\subsection{Materials Properties of the models}

All models details depend on the numerical model B2J-U (U-jacket model) with remodeling the properties of the concrete jacket according to the cases under study. 
Moreover, the original beam model and the U-jacket model have $\mathrm{f}_{\mathrm{y}}$ equals $255 \mathrm{MPa}$ for $\phi 5$ and $570 \mathrm{MPa}$ for $\phi 8$, and f'c equals $42.8 \mathrm{MPa}$ for the concrete jackets while it equals $28.2 \mathrm{MPa}$ for the original concrete beam.

\subsubsection{Materials Properties of Case. a}

The values of the yield strength $\mathrm{f}_{\mathrm{y}}$ in the $\mathrm{U}$-jacket model has been changed to $420 \mathrm{MPa}$ rather than what there is in the U-jacket model $255 \mathrm{MPa}$ and $570 \mathrm{MPa}$ for $\phi 5$ and $\phi 8$ respectively, with the same thickness $2.5 \mathrm{~cm}$ and the same $\mathrm{f}_{\mathrm{c}}$ for the jacket which equals $42.8 \mathrm{MPa}$, and for the original beam which equals $28.2 \mathrm{MPa}$.

\subsubsection{Materials Properties of Case. $b$}

There is a change for type of rebars used for $\mathrm{RC}$ jackets from $5 \mathrm{~mm}$ to $8 \mathrm{~mm}$ with the same characteristics in Case. a.

\subsubsection{Materials Properties of Case. c}

There is a change for type of rebars used for RC jackets from $5 \mathrm{~mm}$ to $10 \mathrm{~mm}$ with the same characteristics in Case a.

\subsubsection{Materials Properties of Case. $d$}

The value of concrete strength f'c of the RC jacket has been changed to $40 \mathrm{MPa}$ with the same thickness $2.5 \mathrm{~cm}$. In addition, $\mathrm{f}^{\prime} \mathrm{c}$ of the original beam has been changed to $20 \mathrm{MPa}$ with the same characteristics in Case .a

\subsubsection{Materials Properties of Case. e}

The value of concrete strength f'c of the RC jacket has been changed to $50 \mathrm{MPa}$ with the same thickness $2.5 \mathrm{~cm}$. In addition, f'c of the original beam has been changed to $20 \mathrm{MPa}$ with the same characteristics in Case .a.

\subsubsection{Materials Properties of Case. $f$}

The value of concrete strength f'c of the RC jacket has been changed to $60 \mathrm{MPa}$ with the same thickness $2.5 \mathrm{~cm}$. In addition, f'c of the original beam has been changed to $20 \mathrm{MPa}$ with the same characteristics in Case .a.

\subsubsection{Materials Properties of Case. $\mathbf{g}$}

The thickness of the RC jacket equals $2.5 \mathrm{~cm}$ with rebar $10 \mathrm{~mm}(\phi 10)$ and concrete strength f'c equals $60 \mathrm{MPa}$, yield strength fy equals $420 \mathrm{MPa}$.

\subsubsection{Materials Properties of Case. $h$}

The thickness of the $\mathrm{RC}$ jacket has been changed to $5 \mathrm{~cm}$ rather than $2.5 \mathrm{~cm}$ with the same characteristics in Case.g.

\subsubsection{Materials Properties of Case. $\mathbf{i}$}

The thickness of the $\mathrm{RC}$ jacket has been changed to $10 \mathrm{~cm}$ rather than $2.5 \mathrm{~cm}$ with the same characteristic in Case.g.

\subsection{Boundary Condition and Applied Load}

Characteristics of the boundary condition and applied load can be summarized in the following points and in (Fig. 2):

1. The beam self-weight was taken into consideration in this numerical modeling. 
2. The simple beam rested on two supports (hinged and roller) as well as it subjected to two-point load.

3. Length of the rectangular beam is $1600 \mathrm{~mm}$ and its cross section for B2J-U (U-jacket model) are $175 \times 225 \mathrm{~mm}$.

4. Distance between the supports is $1400 \mathrm{~mm}$, the distance between the two-point load is $200 \mathrm{~mm}$ and shear span equals $600 \mathrm{~mm}$.

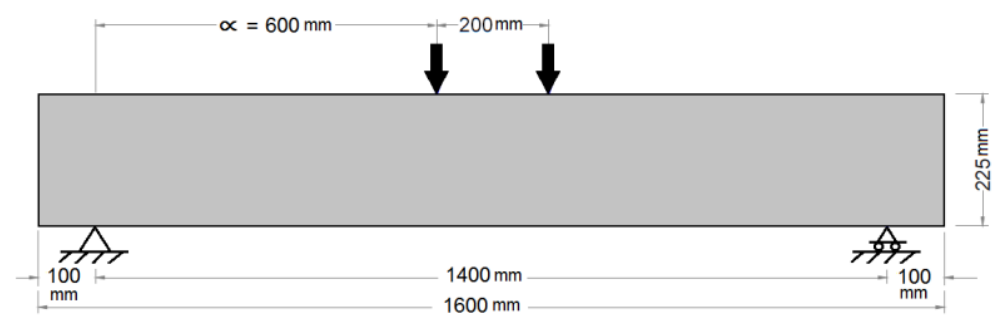

Fig. 2: Geometry, loading, and beam dimension - simply supported beam.

\subsection{Model Mesh, Type of Analysis, Types of Element}

Characteristics of the model mesh and type of analysis can be summarized in the following points:

1. The model was constructed numerically by fine and coarse meshes as shown in (Fig. 3).

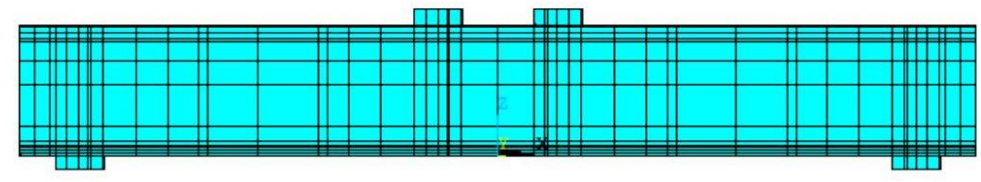

Fig. 3: Finite element mesh, strengthened beam (U-jacket model).

2. Three types of finite element (Fig. 4) were used in the model:

a. Type no.1: LINK 180 element which represents rebar and reinforcement generally.

b. Type no.2: SOLID 65 element which represents concrete.

c. Type no.3: SOLID 45 element which represents supports and loads.

a) LINK180

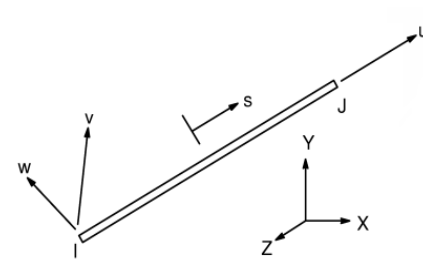

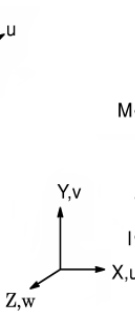

b) SOLID65

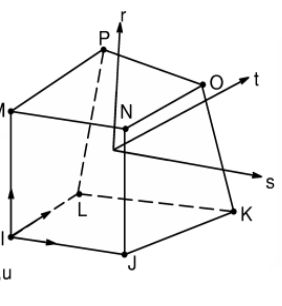

c) SOLID45

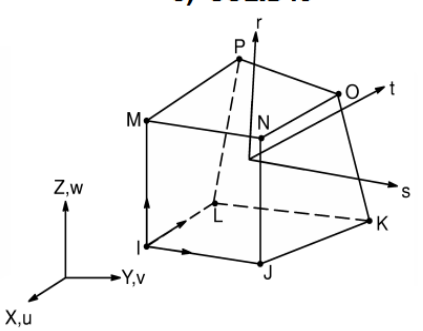

Fig. 4: Geometry of elements: Link180, Solid65, and Solid45 [9].

3. Nonlinear static analysis was performed in the modeling.

4. Displacement control has relied which depended on increasing the displacement and recording data of the applied load sequentially as a method in constructing load-deflection curve.

5. Table 2 shows details of the model mesh such as number of finite element and nodes. 
Table 2: Number of elements and nodes generated in model mesh for reinforced model.

\begin{tabular}{|c|c|c|c|}
\hline Description & No, of Element & No. of Nodes & Element Type \\
\cline { 1 - 3 } Original beam concrete & 2400 & 3234 & \multirow{2}{*}{} \\
\cline { 1 - 3 } U- jacket concrete & 4320 & 5880 & \multirow{2}{*}{ Original beam reinforcement } \\
\cline { 1 - 3 } U- jacket reinforcement & 276 & 282 & 376 \\
\hline
\end{tabular}

\section{Validation of Numerical Model}

Depending on test results, load capacity of the beam before jacketing is $36.4 \mathrm{kN}$, it reaches $55.2 \mathrm{kN}$ after jacketing. The numerical modeling presents similar results of the experimental test indicated.

As a result of validation process, the load capacity $\left(\mathrm{P}_{\mathrm{u}}\right)$ for the $\mathrm{U}$-jacketed beam $(\mathrm{B} 2 \mathrm{~J}-\mathrm{U})$ equals $55.2 \mathrm{kN}$ in the experimental test, and it equals $51 \mathrm{kN}$ by numerical analysis.

As an additional process of validation, the load capacity $\left(\mathrm{P}_{\mathrm{u}}\right)$ for the original beam (B2) equals $36.4 \mathrm{kN}$ in the experimental test, and it equals $34 \mathrm{kN}$ by numerical analysis.

This result indicates to a good agreement between the experimental and numerical results. That means the numerical model has verified as shown in (Table 3), (Fig. 5) and (Fig. 6).

Table 3: Experimental test results.

\begin{tabular}{|c|c|c|c|c|}
\hline Beam name & $\mathrm{P}_{\text {flex }}(\mathrm{kN})$ & $\mathrm{P}_{\text {diag }}(\mathrm{kN})$ & $\mathrm{P}_{\mathrm{u}}(\mathrm{kN})$ & $\Delta \mathrm{P}_{\mathrm{u}}(\mathrm{mm})$ \\
\hline B2 & 13.7 & 25.8 & 36.4 & 16.06 \\
\hline B2J-U & 22.3 & 32.3 & 55.2 & 38.85 \\
\hline
\end{tabular}

There is increasing in the load capacity by dint of increasing cross section of RC beam (U-jackets). Fig. 5 and Fig. 6 refer to about 50\% increase in the applied load of the jacketed beam (B2J-U) compared with the original beam (B2). In addition, they show a comparison between the results of the numerical analysis and the experimental tests. This matching confirms that the numerical modeling is validated.

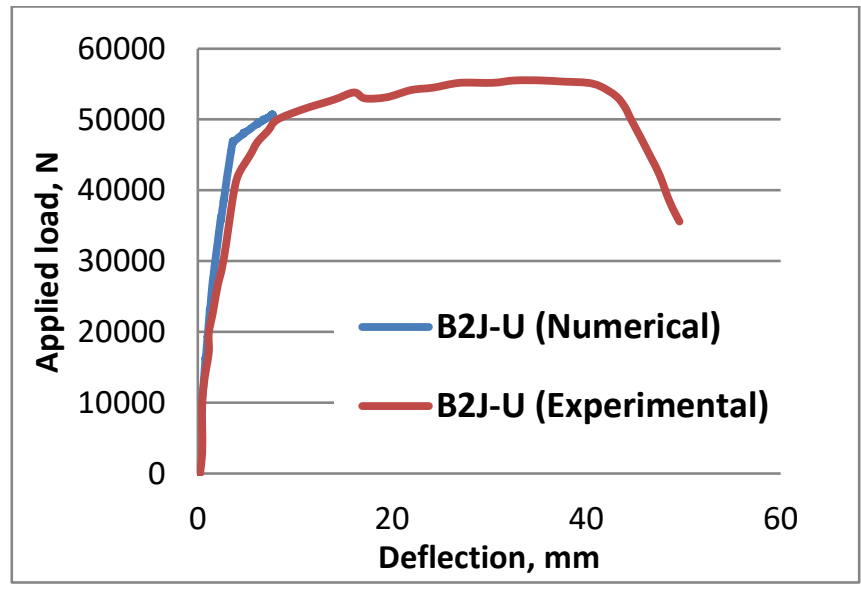

Fig. 5: Verification of B2J-U (U-jacket model).

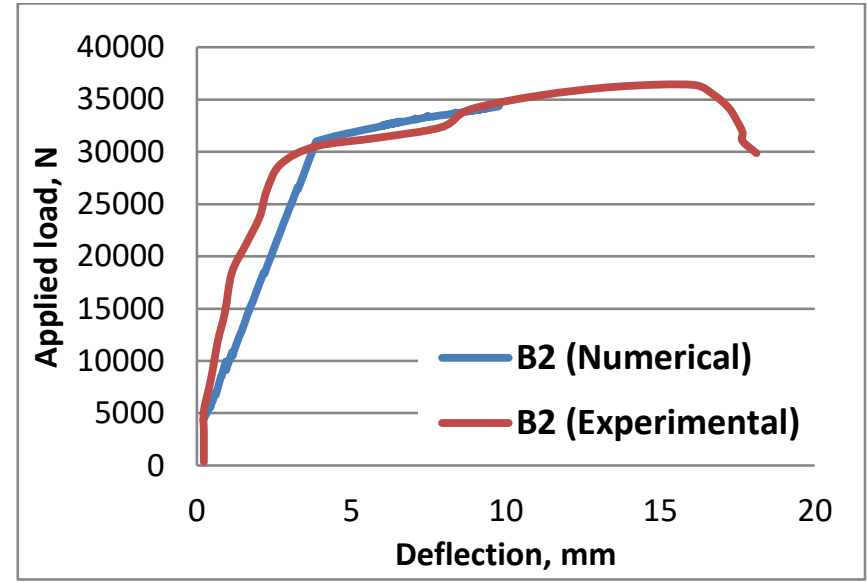

Fig. 6: Verification of B2 (Original beam model).

\section{Numerical Results}

All nine numerical models that mentioned in section 2.1 have constructed using ANSYS software which is finite element modeling. The load capacity of all cases has been compared to the U-jacket model as shown in (Table 4). and (Fig. 7). Fig. 8-11 show structural behavior for all models. 
Table 4: The load capacity of the beam models.

\begin{tabular}{|c|c|c|c|c|c|c|}
\hline Model name & $\begin{array}{c}\text { Original } \\
\text { Model }\end{array}$ & $\begin{array}{c}\text { U-Jacket } \\
\text { Model }\end{array}$ & Case.a & Case.b & Case.c & Case.d \\
\hline $\begin{array}{c}\text { Load } \\
\text { capacity(kN) }\end{array}$ & 34 & 51 & 54 & 93 & 128 & 53 \\
\hline Model name & \multicolumn{2}{|c|}{ Case.e } & Case.f & Case.g & Case.h & Case.i \\
\hline $\begin{array}{c}\text { Load } \\
\text { capacity(kN) }\end{array}$ & \multicolumn{2}{|c|}{53} & 53 & 128 & 142 & 157 \\
\hline
\end{tabular}

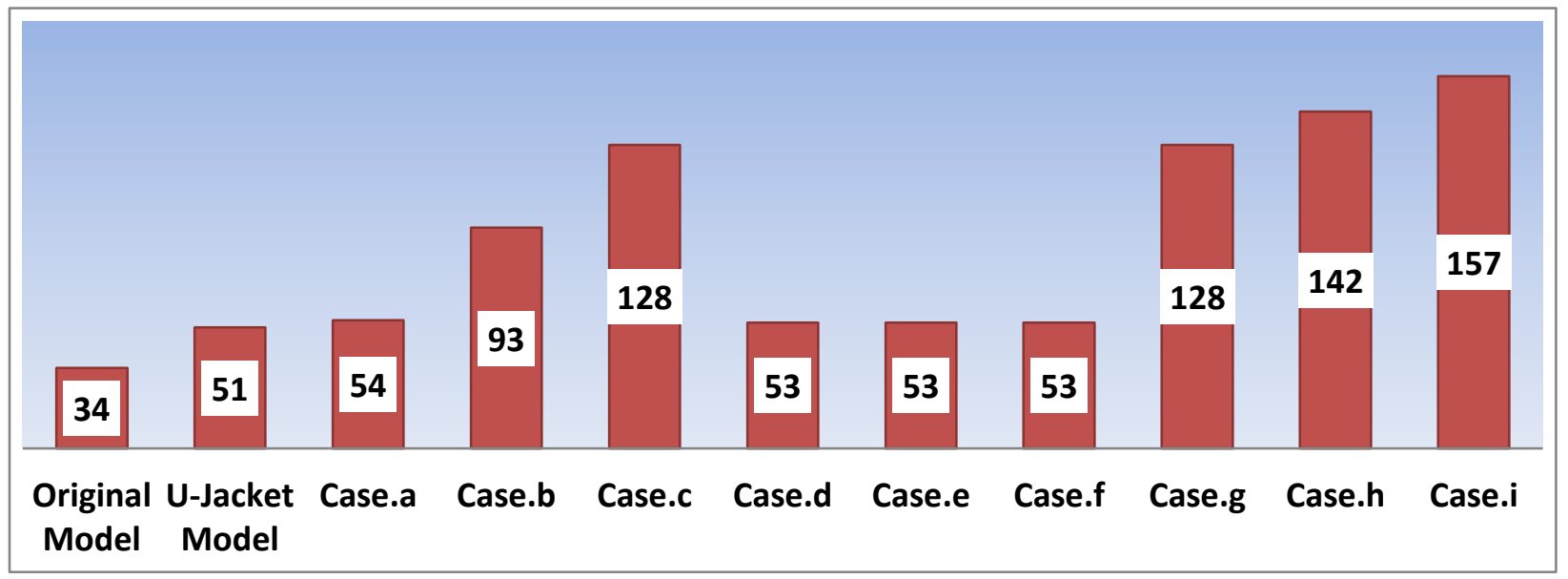

Fig. 7: Results of the load capacity in $\mathrm{kN}$ for the models.

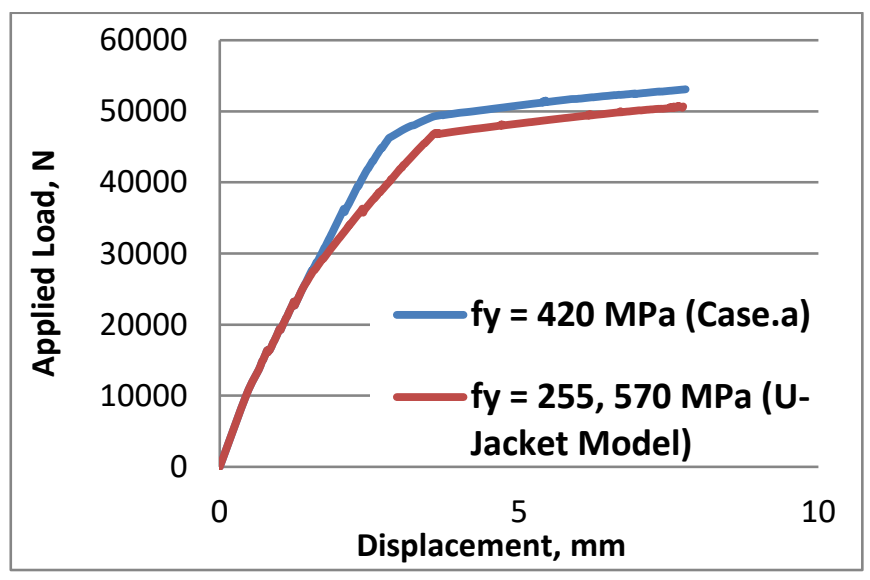

Fig. 8: Effect of changing yield strength $\left(\mathrm{f}_{\mathrm{y}}\right)$.

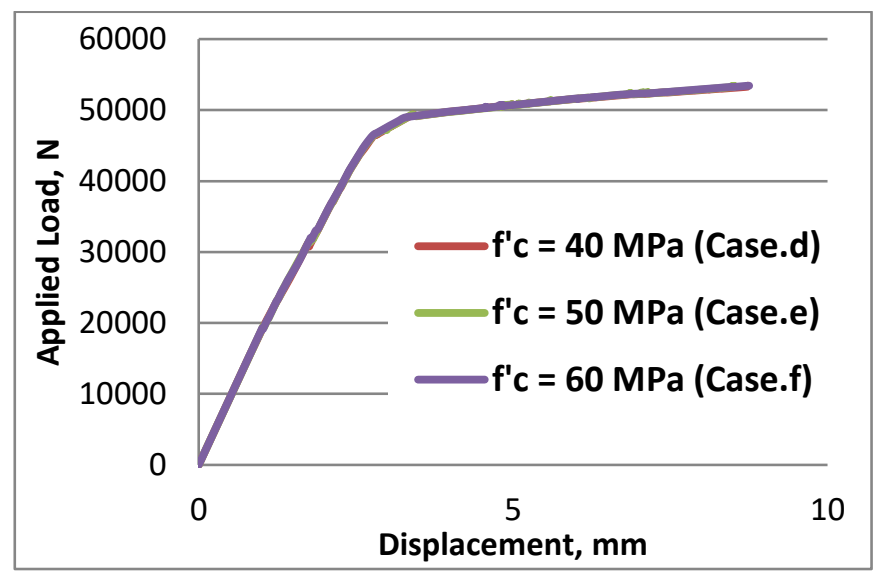

Fig. 9: Effect of changing concrete strength ( $\left.f^{\prime} c\right)$. 


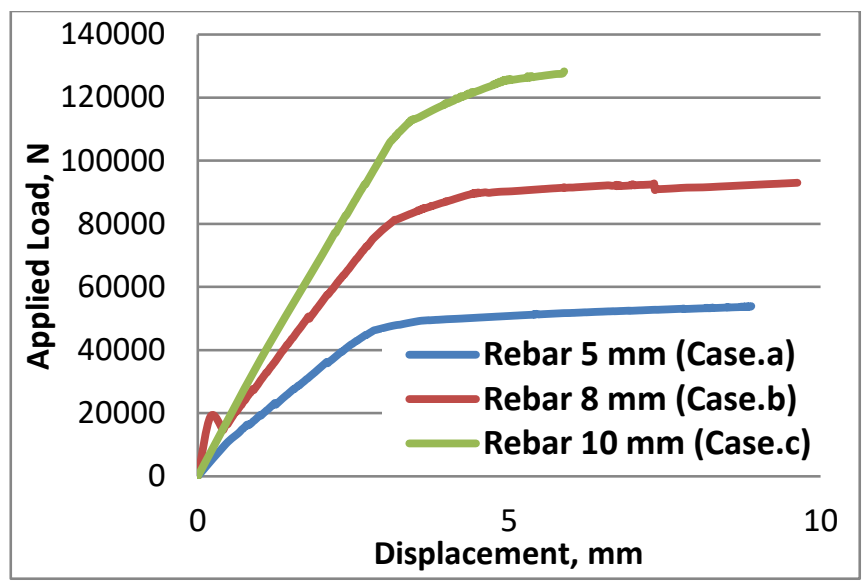

Fig. 10: Effect of changing rebar size (mm).

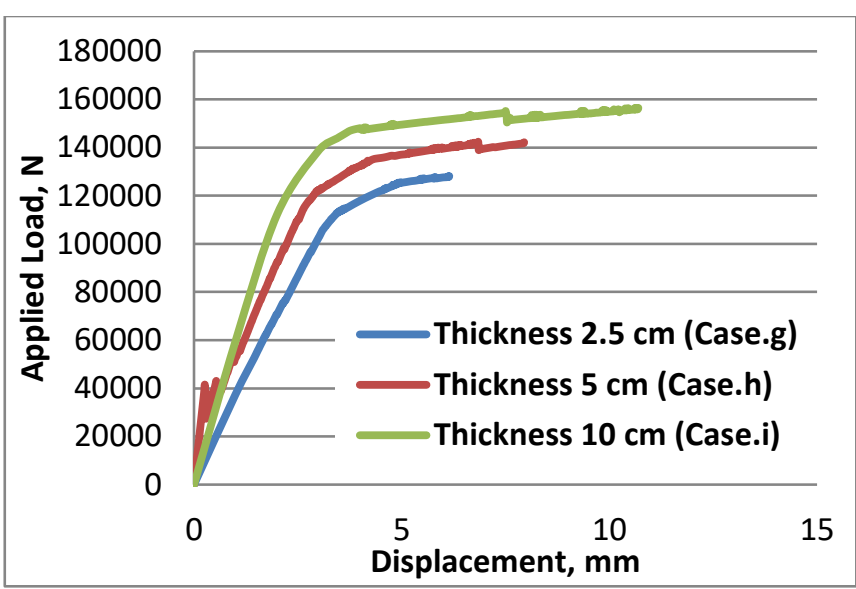

Fig. 11: Effect of changing jacket thickness (cm).

\section{Conclusion}

This study concluded a number of items that can be summarized in the following:

1. Increasing the concrete strength of the RC jackets has no observed effect on the load capacity.

2. Changing the yield strength of the models has a small increase of $6 \%$.

3. There is an increase in the load capacity due to change of the rebar size for the RC jacket where it reaches to $137 \%$ with using rebar $10 \mathrm{~mm}$ rather than $5 \mathrm{~mm}$ as well as it reaches to $276 \%$ compared to the original beam model.

4. It indicated an increase that has been observed due to increase of the RC jacket thickness where it reaches to $21 \%$ with using $10 \mathrm{~mm}$ rather than $2.5 \mathrm{~mm}$ as well as it reaches to $362 \%$ compared to the original beam model.

\section{References}

[1] J. Rupp, "Modeling of steel-jacketed reinforced concrete under axial compressive loads," Master's thesis, The Ohio State University, Columbus, OH, 2012.

[2] B. S. Al-Azzawi, "Fatigue of Reinforced Concrete Beams Retrofitted with Ultra-High Performance FibreReinforced Concrete," Ph.D thesis, Cardiff University, 2018.

[3] C. Oucif, K. Ouzaa, V. Stoian, and C. A. Dăescu, "Numerical modeling of reinforced concrete strengthened columns under cyclic loading," Arabian Journal for Science and Engineering, vol. 42, no. 9, pp. 3933-3944, 2017.

[4] J. Galbo, "Fiber Reinforced Polymer (FRP) for the Repair \& Retrofit of Existing Structures \& for New Construction," Master's Thesis, Cooper Union, New York, 2012.

[5] S. Bousias, A. L. Spathis, M. N. Fardis, and D. Biskinis, "Concrete or FRP jacketing of concrete columns for seismic retrofitting," Advances in Earthquake Engineering for Urban Risk Reduction, pp.33-46, 2006.

[6] N. Gupta, P. Dhiman, and A. Dhiman, "Design and Detailing of RC Jacketting for Concrete Columns," IOSR Journal of Mechanical and Civil Engineering, vol. 12, no. 6, pp. 54-58, 2015.

[7] K. Holschemacher, S. Iqbal, A. Ali and T. A. Bier, "Strengthening of RC beams using lightweight self-compacting cementitious composite," Procedia Engineering, vol. 172, pp. 369-376, 2017.

[8] Q. Khalaf, "Comparative Study for Strengthening Techniques of RC Beams Using Concrete Jackets and Steel Plates," Master's Thesis, Islamic University of Gaza, 2015.

[9] ANSYS, Theory reference, release 19.0, ANSYS, Inc., USA, Academic Edition, 2018.

[10] C. E. Chalioris, G. E. Thermou and S. J. Pantazopoulou, "Behaviour of rehabilitated RC beams with selfcompacting concrete jacketing - analytical model and test results," Construction and Building Materials, vol. 55, pp. 257-273, 2014. 
[11] B. F. Al-Harbi, G. A. Al-Saadi and A. F. Elragi, "Effect of Configurations of Partial Concrete Jacketing on Behavior of Strengthened Beam," International Journal of Civil Engineering and Technology (IJCIET), vol. 9, no. 10, pp. 600-610, 2018.

[12] R. Venu, B. Suraj and G. V. Ramana, "Effects of nitric acid on durability characteristics of M60 self compacting concrete," International Journal of Civil Engineering and Technology (IJCIET), vol. 9, pp. 401-407, 2018.

[13] Saudi Building Code (SBC) National Committee (2018, October 23), Saudi Concrete Structures Code - SBC 304 A, Saudi Arabia [Online]. Available: https://www.sbc.gov.sa 